\title{
Fuzzy Rule based Modeling of Drilling Parameters for Tool Wear in Drilling GFRP Composites
}

\author{
P. Sengottuvel ${ }^{1 *}$ and K. Jessy ${ }^{2}$ \\ 1'Department of Mechatronics Engineering,Bharath University, Chennai-600073, Tamil Nadu, India; \\ sengottuvel.mt@bharathuniv.ac.in \\ 2Department of Mechanical Engineering, K.C.G.College of Technology, Chennai-600097, Tamil Nadu, India; \\ jessy_kg@yahoo.com
}

\begin{abstract}
The most recent development of high performance fibers has led to the availability of composites which can compete and indeed replace metals. Just like any other engineering material GFRP's have to be machined as well. Amongst the three machining operations of turning, milling and drilling, the latter is the most important. Drilling of GFRP is different from traditional metal machining because of the following concerns. In machining of GFRP the drill bit experiences variable thrust forces that produces excess vibration results in poor tool life. Apart from force fluctuations, cutting tools also experience severe abrasion on the flank surface, due to encounter with hard glass fiber. In this work, experiments were conducted in CNC milling machine for carbide drill bit based on L9 orthogonal array. The process parameters investigated are spindle speed, feed rate, and drill diameter. Fuzzy rule based model is developed to predict the thrust force in drilling GFRP. The results indicated that the model can be effectively used for predicting the response variable by means of which tool wear can be controlled.
\end{abstract}

Keywords: Drilling, Fuzzy Logic, GFRP Composites, Thrust Force, Toolwear

\section{Introduction}

Glass fiber reinforced composites are perhaps the most commonly used ranging in application from helmets, fishing boats, automobiles body and aircraft structures due to their high strength, high stiffness, low weight, low thermal expansion and good dimensional stability. GFRP composites are characterized by high strength and rigidity coupled with low weight and, in many respects, they are superior to metals Davim (2004). However, the glass fiber constituent often renders the machining of GFRP difficult. Drilling operations involve cutting holes in the raw materials using rotating cutters called drilling machines or drilling presses. It includes drilling holes which enables the GFRP composites to be incorporated and assembled in structural elements. Drilling of GFRP is essential for assembly or fabrication process. During drilling GFRP the tool continuously encounters alternate matrix and fiber materials, whose response to machining can vary greatly, experiencing force fluctuations and consequent deterioration in tool performance stated by Velayudham (2005).

Thrust force is an important parameter related to the drilling tool that is found life of the tool. It also affects the extent of delamination suffered by the composite material. Abrate et al (1992) stated that the thrust force and torque formed during drilling have important information connected to quality of the hole and wear of the drill bit. Lin et al (1996) carried out a study on drilling composite material at high speed and accomplished that an

*Author for correspondence 
increase of the cutting velocity leads to an increasing drill wear that in turn provokes an increase in the thrust force. By the research of Saghizadeh and Dharan (1986) who identified that the thrust force is a function of the speed of drilling and the feed rates., when feed rates are increased thrust forces also increase resulting in larger amounts of delamination.

The experimental work conducted by Inoue (1997) involved drilling of a Glass Fiber Reinforced Plastic (GFRP) with a cemented carbide drill ( $1 \mathrm{~mm}$ diameter). The author concluded that due to the pre-drilled hole to $0.4 \mathrm{~mm}$ or above, thrust force is drastically reduced. Palanikumar et al (2006) used fuzzy logic for optimizing the multiple performance characteristics. Latha and Senthil Kumar (2009) have successfully applied fuzzy logic for the prediction of delamination in drilling glass fibre reinforced plastics. Yue jiao et al (2004) and Sengottuvel et al (2013) used fuzzy adaptive networks in machining process modeling. They have used fuzzy logics for surface roughness prediction in turning operations.

In the present work a user friendly fuzzy logic based system has been designed for the prediction of thrust force in drilling GFRP composites. The experiments were conducted on CNC milling machine. Carbide drill bit of various diameters is used for the investigation. $\mathrm{L}_{9}$ orthogonal array is used for experimentation. Thrust force and tool wear were obtained as output parameter. The results indicated that the fuzzy logic model can be effectively used for drilling of composites.

\section{Experimental Work}

The drilling test were performed on Hass SSYT USA model CNC milling machine with maximum torque 102 Nm@1400 rpm, maximum power rating $20 \mathrm{HP}$ and maximum feed rates $25.4 \mathrm{~m} / \mathrm{min}$. Figure 1 represents the experimental setup.

\subsection{Cutting Tools and Specimen Preparation}

A total of nine uncoated carbide drill bits, three drill bits of diameter $6 \mathrm{~mm}, 8 \mathrm{~mm}$ and $10 \mathrm{~mm}$ were used in this experiment. The performance of each drill bit was examined and monitored for nine conditions of feed rate and speed of spindle rotation. The dimensional properties of the drilling tool are tool overhang $47 \mathrm{~mm}$, point angle $140^{\circ}$, helix angle $30^{\circ}$ and Shank type is cylindrical. In

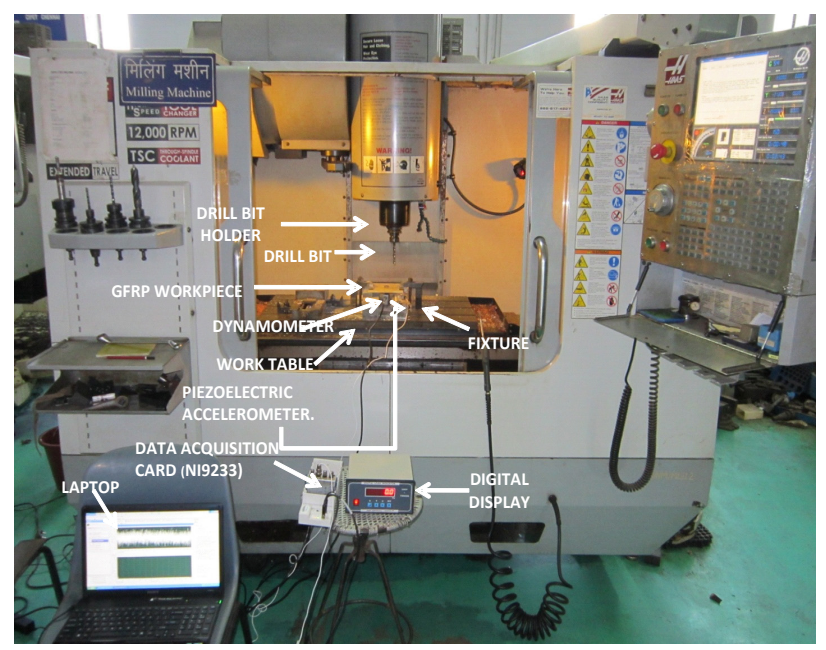

Figure 1. CNC Milling Machine and Thrust Force Measurement Setup.

these experiments, the GFRP specimen with dimensions $150 \times 150 \times 8 \mathrm{~mm}$ prepared through Compression moulding technique and used as work piece. High strength 360 CSM OCV Make Glass Mat was used as reinforcement in epoxy resin with araldite as hardener and processed to a temperature of $155^{\circ} \mathrm{C}$ to $160^{\circ} \mathrm{C}$ for approx 35 minutes to fabricate GFRP.

\subsection{Cutting Conditions}

The experiment was tested for three levels of feed rates, spindle speeds and Drill diameter. All these three levels are summarized in Table 1. The Taguchi methodology for three factors at each of these three levels was used for the implementation of the plan of experiments. The cutting condition was selected from ASM machining composites data book.

Table1. Three Levels of Testing the Experiment

\begin{tabular}{|c|c|c|c|c|}
\hline Symbol & Factors & Level 1 & Level 2 & Level 3 \\
\hline F & Feed (mm/min) & 5 & 10 & 15 \\
\hline S & $\begin{array}{c}\text { Spindle speed } \\
(\mathrm{rpm})\end{array}$ & 750 & 1000 & 1250 \\
\hline $\mathrm{D}$ & Tool diameter & 6 & 8 & 10 \\
\hline
\end{tabular}

The orthogonal array selected was L9 $\left(3^{3}\right)$. A total of 9 experiments were carried out considering speed, feed and coolant pressure for drilling each experiment has been repeated for three times and the thrust force was recorded for each experiment. 


\subsection{Thrust Force and Tool Wear Measurement}

The thrust force developed in drilling the composite material was measured using Drill tool dynamometer. The drilling thrust force values are stored in laptop for further analyses. Tool wear is determined by measuring the wear as it develops, specifying the effective cutting time elapsed before a stipulated degree of wear is reached. Tool wear were measured using profile projector.

\section{Fuzzy Rule Based Model for Thrust Force in Drilling GFRP Composites}

A fuzzy logic unit consists of a fuzzifier, membership functions, a fuzzy rule base, an inference engine, and a defuzzifier. The input and output values are fuzzified using membership functions. The fuzzy reasoning works on fuzzy rules to generate a fuzzy value to be used by inference engine. Finally, fuzzy value is converted into a crisp output by defuzzifier. In this work, defuzzification is done according to the Centre of Area (COA) method. Two fuzzy models namely mamdani and sugeno are available. Sugeno outputs are used for linear or constant; for others the mamdani is preferred. Between the two, Mamdani fuzzy inference is used in modeling the process parameters due to the non-liner relation with outputs. Modeling of thrust force was done by using MATLAB R2011b software ${ }^{1}$.

\subsection{Fuzzy Expression}

For the prediction of output parameters such as thrust force the drilling operation depends on three input parameters, namely Federate, Speed and Tool, diameter.

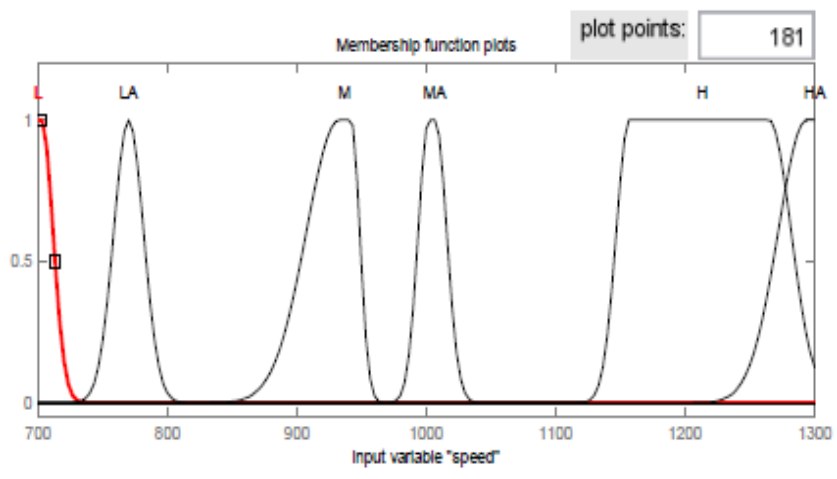

Figure 2. Membership Function for Input Parameter Spindle Speed.
The first step in establishing the algorithm for fuzzy model is to choose the fuzzy sets of the process variables ${ }^{2}$.

\subsection{Degree of Membership Functions of Input and Output Variables}

The first step in generating a fuzzy logic is to identify the ranges of input and output variables. Then, the range of each process variable is divided into groups of fuzzy subsets. Each fuzzy subset is given a proper name and assigned a membership function ${ }^{3}$.

The membership function is assigned without depending on the results of the experiments. In the MATLAB R2011b, the maximum number of membership function levels available is 9. Six levels membership functions are considered in this work ${ }^{4}$. Individual notations are assigned to each membership value based on our need. The notations used in fuzzy subsets were as follows for spindle speed, feed rate and tool diameter are: L-LOW, LA-LOW AVERAGE, M-MEDIUM, MA-MEDIUM AVERAGE, H-HIGH AND HA-HIGH AVERAGE as shown Figure 2,3 and $4^{5}$. More precise results can be obtained by using more number of membership functions. The maximum thrust force values for each experiment is used for fuzzy logic rule based modeling of drilling parameters in drilling GFRP composites ${ }^{6}$.

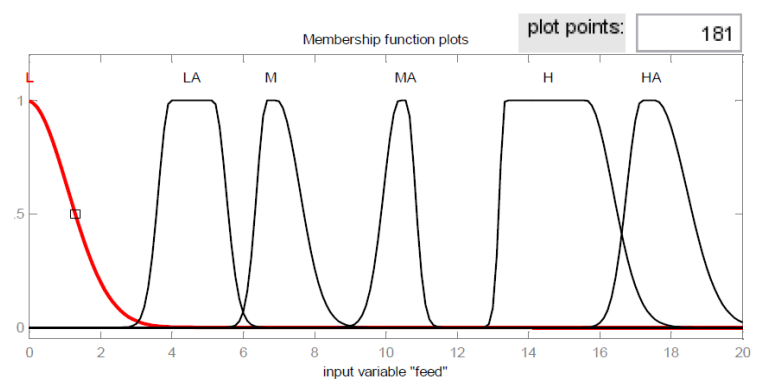

Figure 3. Membership Function for Input Parameter Feed Rate.

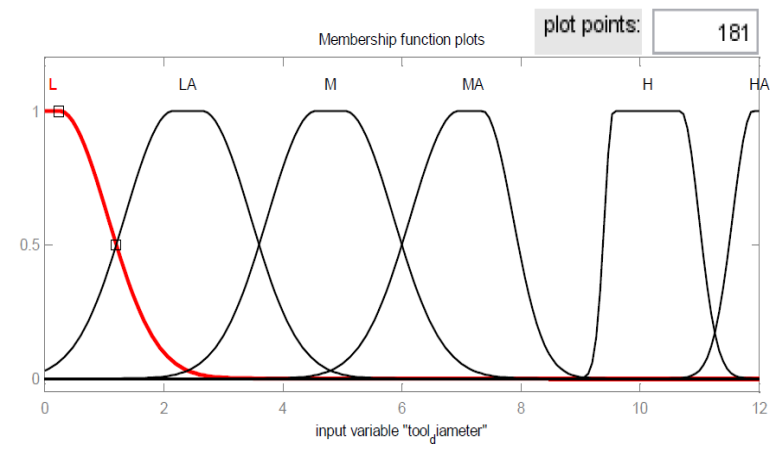

Figure 4. Membership Function for Input Parameter Drill Diameter. 


\section{Results and Discussion}

The tensile strength of composites is up to six times greater than that of conventional materials with higher strength to weight ratios ${ }^{7}$. They have high torsional strength and impact properties. Their ability to withstand fatigue is $60 \%$ higher than that of conventional materials. In addition they are up to $45 \%$ lighter than aluminum structures with low embedded energy levels. The thrust force developed in drilling is an important concern ${ }^{8}$.

Table 2 shows the influence of thrust force and tool wear for $10 \mathrm{~mm}$ diameter drill bit for all the nine experiment ${ }^{9}$.

Table 2. Thrust force and Tool wear values for each Experiment for $10 \mathrm{~mm}$ diameter drill bit

\begin{tabular}{|c|c|c|c|c|c|}
\hline $\begin{array}{c}\text { Exp. } \\
\text { No }\end{array}$ & $\begin{array}{c}\text { Feed } \\
(\mathbf{m m} / \mathbf{m i n})\end{array}$ & $\begin{array}{c}\text { Speed } \\
(\mathbf{r p m})\end{array}$ & $\begin{array}{c}\text { Thrust } \\
\text { Force } \\
(\mathbf{K g F})\end{array}$ & $\begin{array}{c}\text { Tool } \\
\text { wear } \\
(\mathbf{m m})\end{array}$ & Time(secs) \\
\hline 1 & 5 & 750 & 10 & 0.91 & 61.4 \\
\hline 2 & 5 & 1000 & 13 & 0.956 & 60.35 \\
\hline 3 & 5 & 1250 & 14 & 0.9565 & 60.32 \\
\hline 4 & 10 & 750 & 12 & 0.921 & 30.92 \\
\hline 5 & 10 & 1000 & 14 & 0.974 & 30.84 \\
\hline 6 & 10 & 1250 & 19 & 0.9 & 20.52 \\
\hline 7 & 15 & 750 & 17 & 0.986 & 30.8 \\
\hline 8 & 15 & 1000 & 20 & 0.99 & 20.28 \\
\hline 9 & 15 & 1250 & 21 & 1.010 & 19.26 \\
\hline
\end{tabular}

From the above Table 2 it is observed that average thrust force for all the experiment is around $15.5 \mathrm{Kg} \mathrm{F}$. The range of thrust force varies from $10 \mathrm{KgF}$ to $21 \mathrm{KgF}$. The average maximum thrust force $21 \mathrm{KgF}$ was recorded at $9^{\text {th }}$ experiment, since the speed and feed given is high. In the same way average minimum thrust force $10 \mathrm{KgF}$ was recorded at $1^{\text {st }}$ experiment. Since the speed and feed given is very less when compared to other experiments ${ }^{10}$.

During the experiment numbers 1 to 3 , feed is kept constant $5 \mathrm{~mm} / \mathrm{min}$ and speed varied to $750 \mathrm{rpm}, 1000$ $\mathrm{rpm}$, and $1250 \mathrm{rpm}$ as a result thrust force and drill wear increases gradually from $1^{\text {st }}$ experiment to $3^{\text {rd }}$ experiment due to significant increase in the speed ${ }^{11}$. Similar inference can be referred in the Table 2 for $4^{\text {th }}$ to $6^{\text {th }}$ experiment as well as $7^{\text {th }}$ to $9^{\text {th }}$ experiment. During the experiment numbers 4 to 9 , feed is more and hence the machining time is less as, when compared to experiment numbers 1 to 3 as shown in Table 2. Since the machining time is less the cutting edges of the drill bit is subjected to severe shock leading to high thrust force and tool wear. This shows the significance of feed towards thrust force in drilling ${ }^{12}$.

Table 3. Thrust force and Tool wear values for various diameter drill bit

\begin{tabular}{|l|c|c|c|c|c|}
\hline $\begin{array}{l}\text { Feed } \\
(\mathbf{m m} / \mathbf{m i n})\end{array}$ & $\begin{array}{c}\text { Speed } \\
(\mathbf{r p m})\end{array}$ & $\begin{array}{c}\text { Drill } \\
\text { Diameter } \\
(\mathbf{m m})\end{array}$ & $\begin{array}{c}\text { Thrust } \\
\text { Force } \\
(\mathbf{K g F})\end{array}$ & $\begin{array}{c}\text { Tool } \\
\text { wear } \\
(\mathbf{m m})\end{array}$ & $\begin{array}{c}\text { Time } \\
(\mathbf{s e c s})\end{array}$ \\
\hline 5 & 750 & 10 & 10 & 0.91 & 61.4 \\
\hline 5 & 1000 & 8 & 9 & 0.755 & 60.35 \\
\hline 5 & 1250 & 6 & 7 & 0.525 & 60.32 \\
\hline 10 & 750 & 10 & 12 & 0.921 & 30.92 \\
\hline 10 & 1000 & 8 & 11 & 0.815 & 30.84 \\
\hline 10 & 1250 & 6 & 9 & 0.63 & 20.52 \\
\hline 15 & 750 & 10 & 14 & 0.986 & 30.8 \\
\hline 15 & 1000 & 8 & 12 & 0.921 & 20.28 \\
\hline 15 & 1250 & 6 & 11 & 0.631 & 19.26 \\
\hline
\end{tabular}

From the Table 3 it is observed the thrust force value for $6 \mathrm{~mm}$ drill bit in cutting condition 3 is $14 \mathrm{KgF}$ where as for cutting condition 6 and 9 is $19 \mathrm{KgF}$ and $21 \mathrm{KgF}$. This shows the significance of feed in thrust force when the speed is constant. Similar observation is observed for $8 \mathrm{~mm}$ and $10 \mathrm{~mm}$ diameter drill bit. Similarly we can observe an increase in drill wear due to increase in cutting condition and increase in drill diameter ${ }^{13}$. This is due to increase in the chisel edge length for larger diameter drill bit compared to smaller diameter drill. Hence we can observe a decrease in thrust force and tool wear in cutting condition I for speed 750rpm and feed $5 \mathrm{~mm} / \mathrm{min}$.

Figure 5 and 6 represent the comparison of experimental and fuzzy results for thrust in drilling composite materials ${ }^{14}$.The results indicated that the thrust force varies with the experimental condition. The graph is drawn for the nine set of experimental condition with respect to thrust force. The tool wear developed in drilling in drilling operation is proportional to the amount of thrust force ${ }^{15}$.

When the tool thrust observed in machining is more it leads to the tool wear. For reducing of thrust force, modeling and optimization of process parameter are required. In this work fuzzy rule based modeling is used for the prediction of thrust force ${ }^{16}$. From the Figure 5 and 6 it can be observed that the results obtained through the fuzzy logic model are almost similar to the experimental results ${ }^{17}$.

To validate the experimental results ,the thrust force was measured for arbitrary cutting condition and validated 


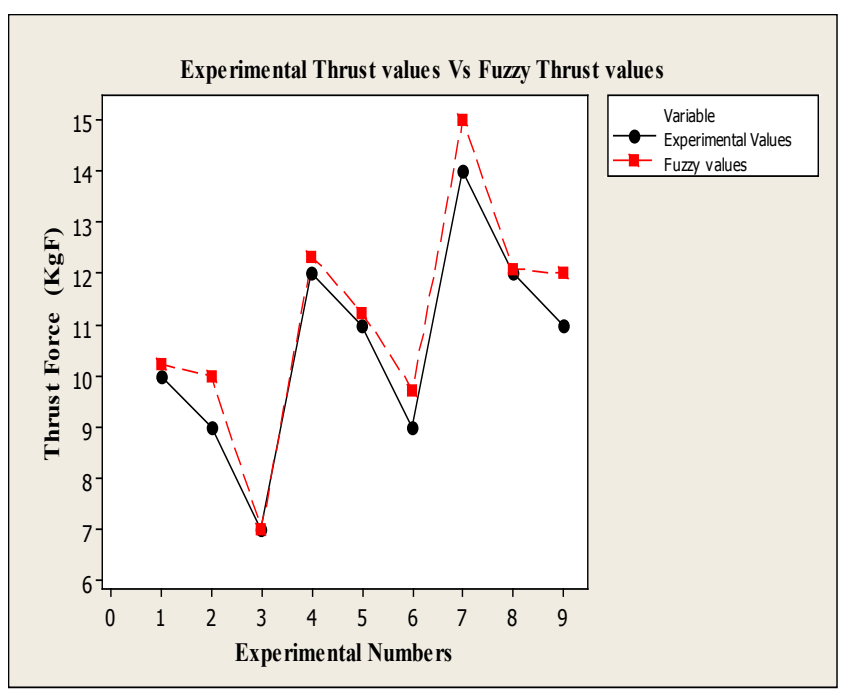

Figure 5. Comparison of Results for Experimental Thrust Force Values and Fuzzy Thrust Force Values (10mm Diameter Drill Bit).

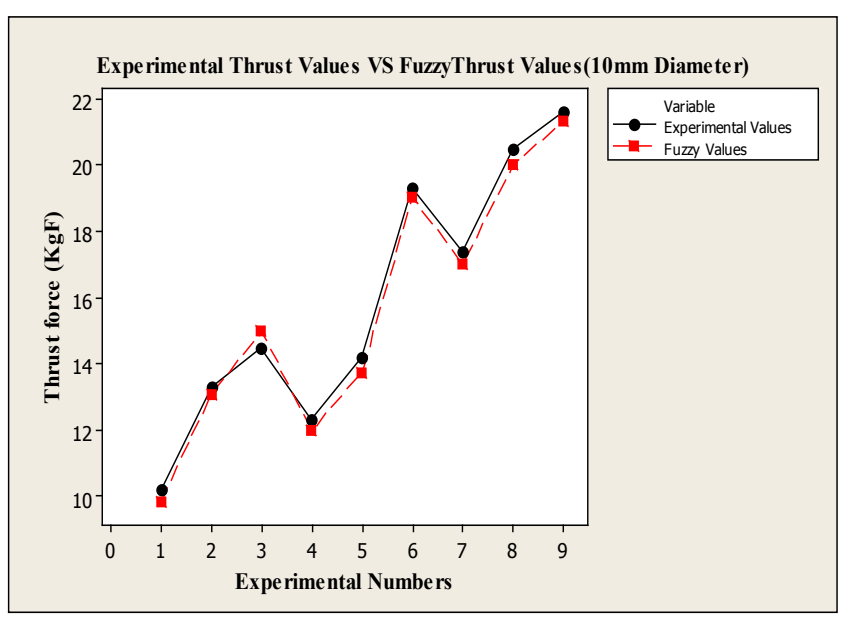

Figure 6. Comparison of Results for Experimental Thrust Force Values and Fuzzy Thrust Force Values.

with the modeling fuzzy based results. It was found that the percentage of error is less than $2 \%{ }^{18}$. Hence fuzzy rule based modeling technique can be effectively used for the prediction of thrust force in drilling GFRP composites ${ }^{19}$.

\section{Conclusions}

The objective of the present was to identify the negative side effects that occur whilst drilling GFRP's. From the literature review, it was identified that due to increase in thrust force the tools get abraded very quickly as compared to metals. Hence in the present work the thrust force and tool wear developed during drilling GFRP composites has been investigated according to L9 orthogonal array experiments. Fuzzy rule based model has been developed for predicting thrust force in drilling GFRP composites. Based on the experimental and fuzzy logic modeling results the following conclusions are drawn.

- Based on the investigation optimized cutting parameter which minimizes thrust force and tool wear during drilling GFRP composites is speed 750rpm and feed $5 \mathrm{~mm} / \mathrm{min}$.

- Lesser diameter drill bits minimize thrust force and tool wear during drilling GFRPs.

- Fuzzy rule based model is best method for predicting the thrust force in drilling GFRP composites.

The present work can be extended to investigate the effect of using different tool materials on the quality of drilled hole in different types of GFRPs.

\section{Reference}

1. Davim JP, Reis CC. Experimental study of drilling glass fiber reinforced plastics (GFRP) Manufactured by hand lay-up. Composite Science Technology. 2004; 64(2):289-97.

2. Velayudham A, Krishnamurthy R. Evaluation of drilling characteristics of high volume fraction fibre glass reinforced polymeric composite. International Journal of Machine Tools and Manufacture. 2005; 45(4-5):399-406.

3. Bharatwaj RS, Vijaya K, Rajaram P. A descriptive study of knowledge, attitude and practice with regard to voluntary blood donation among medical undergraduate students in Pondicherry, India. Journal of Clinical and Diagnostic Research. 2012; 6(S4):602-4. ISSN: 0973-709X.

4. Abrate S, Walton D L. Machining of composite materials. New York: Mc Graw and Hill. Composite manufacturing. 1992. p. 75-83.

5. Lin SC, Chen IK. Drilling of carbon fiber-reinforced composite material at high speed, wear. 1996; 194(1-2): 156-62.

6. Raj MS, Saravanan T, Srinivasan V. A modified direct torque control of induction motor using space vector modulation technique. Middle-East Journal of Scientific Research. ISSN: 1990-9233. 2014; 20(11): 1572-4.

7. Saghizadeh CK, Dharan A. Delamination fracture toughness of graphite and aramid epoxy composites. ASME Journal of Engineering Material Technology. 1986; 108(4): 290-5.

8. Inoue E, Aoyama T, Hirogaski K, Ogawa H, Matushita Y, Kitahara T, Katayama. Influenceof tool wear on internal damage in small diameter drilling in GFRP. Composite Structures. 1997; 39(1):55-62. 
9. Rajasulochana P, Krishnamoorthy P, Dhamotharan R. An Investigation on the evaluation of heavy metals in Kappaphycus alvarezii. Journal of Chemical and Pharmaceutical Research. 2012; 4(6):3224-8. ISSN: 0975-7384.

10. Palanikumar K, Karunamoorthy LK, Karthikeyan R, Latha B. Optimization of machining parameters in turning GFRP composites using a carbide $(\mathrm{k} 10)$ tool based on the taguchi method with fuzzy logic. Metals and Materials International. 2006; 12(6):483-91.

11. Latha B, senthilkumar VS. Fuzzy rule based modeling of drilling parameters for delamination in drilling GFRP composites. Journal of reinforced plastics and composites. 2009 Apr; 28(8):951- 64. DOI :10.2009.

12. Jasmine MIF, Yezdani AA, Tajir F, Venu RM. Analysis of stress in bone and microimplants during en-masse retraction of maxillary and mandibular anterior teeth with different insertion angulations: A 3-dimensional finite element analysis study. American Journal of Orthodontics and Dentofacial Orthopedics. 2012; 141(1):71- 80.ISSN:0889-5406.

13. Jiao Y, Lei S, Pei ZJ, lee ES. Fuzzy adaptive networks in machining process modeling:surface roughness prediction for turning. International Journal of Machine tools and Manufacture. 2004; 44(15):1643-51.

14. Sengottuvel P, Satishkumar S, Dinakaran D. Optimization of Multiple Characteristics of EDM Parameters Based on Desirability Approach And Fuzzy Modeling. Journal of Procedia Engineering. 2013; 64:1069-78.

15. Fuzzy control programming. Technical report. International Electro technical Commission. No 65: industrial process measurement and control; 1997. Available from: http://jfuzzylogic.sourceforge.net/doc/iec_1131_7_ cd1.p df.

16. Zadeh LA. Outline of a new approach to the analysis complex systems and decision processes. IEEE Transactions on Systems, Man and Cybernetics. 1973; 3:28-44.

17. Mahalakshmi K, Prabhakar J, Sukumaran VG. Antibacterial activity of Triphala, GTP and Curcumin on Enterococci faecalis. Biomedicine. 2012 Mar 4. p. 43-46. ISSN: 0970 2067.

18. Pappis CP, Sietto CI. Fuzzy Reasoning. Springer; US. 2005. p. 437-74.

19. Sugeno M, Yasukawa T. A fuzzy-logic-based approach to qualitative modelling. IEEE Transactions on Fuzzy Systems. 1993; 1(1):7-31.

20. Kimio T, Natarajan G, Hideki A, Taichi K, Nanao K. Higher involvement of subtelomere regions for chromosome rearrangements in leukemia and lymphoma and in irradiated leukemic cell line. Indian Journal of Science and Technology. 2012 April; 5(1):1801-11.

21. Cunningham CH. A Laboratory Guide in Virology. 6th ed. Minnesota: Burgess Publication Company; 1973.

22. Sathish Kumar E, Varatharajan M. Microbiology of Indian Desert. In: Sen DN, editor. Ecology and Vegetation of Indian Desert. India: Agro Botanical Publishers; 1990. p. 83-105.

23. Varatharajan M, Rao BS, Anjaria KB, Unny VKP, Thyagarajan S. Radiotoxicity of Sulfur-35. Proceedings of 10th NSRP; India. 1993. p. 257-8.

24. 01 Jan 2015. Available from: http://www.indjst.org/index. php/vision 